Citation: Muroi SK and Bertone E (2019). From Thoughts to Actions: The Importance of Climate Change Education in Enhancing Students' Self-Efficacy. Australian Journal of Environmental Education 35, 123-144. https://doi.org/10.1017/ aee.2019.12 


\title{
From thoughts to actions: the importance of climate change education in enhancing students' self-efficacy
}

\begin{abstract}
The relation between the understanding and belief of the sitespecific dangers of climate change and the behaviour that individuals take to mitigate their impact was assessed to investigate the psychological antecedent to pro-environmental behaviour; a necessity to mitigate anthropogenic climate change at the individual level. A quantitative crosssectional design was employed to measure beliefs and behaviour of university students. Correlation was measured between the belief in one's ability to affect change and pro-environmental behaviour. The hypothesis that nations facing greater climate threat would behave accordingly was tested on the two largest national representatives of the sample, China and Australia. In addition, a naïve Bayesian Network, coupled with a selforganising map, was developed to explore correlations between selfefficacy and participants' socio-demographic features. Results showed that Chinese students are more likely to have higher self-efficacy, while such trend was not noticed for Australians. Similarly, participants with higher educational qualifications, older, and with higher-paid jobs also have a higher chance of presenting pro-environmental behaviour. Despite the study limitations, there seems to be evidence suggesting that educational and climate change policies have affected students' self-efficacy and individual commitment to mitigation.
\end{abstract}


Keywords: Bayesian networks, climate change education, national education policy, self-efficacy

\section{Introduction}

Climate change accelerated by anthropogenic causes throughout the world has been shown to be of significant and ongoing concern for at least over two decades (Santer et al. 1996, Vitousek et al. 1997). The understanding of the interaction between climate and behaviour requires an interdisciplinary approach, including predictive economic models (Dasgupta 2008), predictive climate models (Carleton and Hsiang 2016), and the understanding of relationship between attitudes and behaviour (Lynn and Longhi 2011, Tikir and Lehmann 2011). However, the latter presents several problems for researchers, as knowledge and awareness of environmental issues do not necessarily lead to behavioural outcomes (Hungerford and Volk 1990). Behaviour is not fixed by an individual's beliefs, but it is fluid, dependent on experience, expectations, and social norms, amongst others (Heimlich, Mony, and Yocco 2014). There is further concern that the quest to establish a causal climate change model from belief to behaviour is insensitive to the nuances of individual lives motivated by economic, social, and political factors interspersed amongst climate change beliefs and behaviours (Coutenay-Hall and Rogers 2002). This is evident in the fact that the general population in wealthier countries are aware of climate change, yet they do not see the climate models' predictions as an imminent threat, and thus individual attempt of mitigation of future risks is limited (Swim et al. 2009). Despite the complexity arising from the assumption that beliefs lead to behaviour, research on attitudes towards climate change is useful in helping to predict pro-environmental behaviour (Lynn and Longhi 2011, Semenza et al. 2008, Shove 2010). By understanding the link between beliefs and their subsequent effect on individual behavioural outcome, research could guide effective implementation of climate change 
education, a critical factor in promoting sustainable development (Mochizuki and Bryan 2015, UNESCO 2015, 2016).

\section{Background}

\section{Perception of climate change}

The lack of response by many nations shows a maladaptation to current and future risks caused by the climate. Predictive models show that temperature increase will cause increased mortality, economic damage, decrease in agricultural production, increased electricity consumption, and decreased labour productivity, amongst others (Carleton and Hsiang 2016). Climate change may also cause increased magnitude and frequency of extreme weather events; future combinations of which, due to complex system interactions, may even magnify the impact of a single event, on e.g. drinking water quality (Bertone et al. 2016). Economic inequality, which influences the capability of individuals to survive severe climate disasters, is seen to be a great issue, as the severity of predicted damage that regions will encounter is disproportionately higher in poorer regions globally (Carleton and Hsiang 2016, Garschagen et al. 2016). The regions facing the greatest risk of impact from climate change are often socioeconomically disadvantaged and face a proportionally higher risk due to extreme change in temperature and precipitation (Pachauri et al. 2014). In fact, poverty itself prevents citizens from being able to cope with and survive extreme weather events due to poor infrastructure and poor economic sustainability (Garschagen et al. 2016). Due to the global nature of the issue, a unified approach to combating climate change must include all levels educating the public; from policy makers and organizations, to individuals. 


\section{Climate change policy}

Extensive research has been conducted that reports higher levels of education influence attitudes towards climate change and the development of pro-environmental behaviours (Howell 2014, Lo and Chow 2015, Longhi 2013, Lynn and Longhi 2011, Ockwell, Whitmarsh, and O'Neill 2009, Semenza et al. 2008, Harring and Jagers 2018). Indeed, an individual's willingness to act in pro-environmental ways must be preceded by an awareness of climate change issues, which often necessitates a greater understanding of scientific and statistical data. However, the assumption that a higher level of educational achievement leads to greater awareness does not necessarily imply that an individual will exhibit pro-environmental behaviour, such as with individuals that are aware that a smaller car is the environmentally friendly choice, but would rather buy a larger car to promote their status and wealth (Sternäng and Lundholm 2011), or individuals that choose to buy an affordable house far away from work even though this would increase their carbon footprint in the form of longer commutes (Coutenay-Hall and Rogers 2002). There are growing concerns, however, that individual change is being undermined by political and corporate entities that see no financial incentive in lobbying for climate change initiatives that both directly and indirectly affect their economic interests (Antonio and Brulle 2011, Moisander 2007). The old notion that wealthier countries would be more concerned seems to be negated by the cost of climate disaster mitigation and uncertainty of current and future economic concerns (Kim and WolinskyNahmias 2014). Despite governments realising the future dangers of climate change, policy seems to be grid-locked by a concern for economic prosperity versus ecological sustainability (Antonio and Brulle 2011). Although efforts by many nations to mitigate climate change through policy are in their infancy, there is yet to be a realization of any significant results of mitigation efforts when compared to previous trends of climate 
change at an international scale (Change 2014). Furthermore, there seems to be a lack of action despite calls by researchers arguing the effectiveness of climate change education integrated into the curriculum for over a decade, which have seen limited implementation by governments (Anderson 2013, Pruneau et al. 2003).

\section{Factors relating to individual perception of climate change}

Though pro-environmental behaviour generally aligns with the attitudes towards climate change, various constraints such as economic viability, living with someone having differing attitudes, and availability of infrastructure limit the behavioural outcome that attitude alone depicts (Longhi 2013). Furthermore, awareness of climate change does not translate necessarily into pro-environmental behaviour. Studies about the psychological motivations of behaviours that may not have economic benefits for an individual must also be considered, as other potential inputs may explain the relation between the belief in climate change and whether or not that translates into proenvironmental behaviours (Semenza et al. 2008, Kim and Wolinsky-Nahmias 2014). The public's willingness to support policies that curb climate change through the limiting of greenhouse gas emissions is, in fact, higher than the public's perception on the dangers of climate change (Stokes, Wike, and Carle 2015). Though perhaps, people may generally be inclined to support the morally just option of showing concern for environmental issues when it comes to how others (in this case, the governments) ought to deal with socio-scientific issues (Sternäng and Lundholm 2011).

According to a meta-analysis by Hines, Hungerford, and Tomera (1986/87), other areas antecedent to behaviour include the knowledge of action strategies, verbal commitment, locus of control, and an individual's sense of responsibility as factors aside from awareness and belief. The motivational concept of self-efficacy as described by 
Bandura $(1977,1982,1993)$ is a factor that may strongly influence an individual's behaviour to align with their attitudes and beliefs towards climate change. Indeed, if an individual believes that their actions can positively influence the overall fight against climate change, then according to Bandura (1977, 1982, 1993), their behaviour should correlate with their attitudes even when it is inconvenient to them. In cases such as ridesharing, which requires the individual to spend time and effort to organise and coordinate such behaviour, self-efficacy could be a variable of concern. Self-efficacy could potentially explain findings by Lynn and Longhi (2011) that show education influences behaviour's relation to attitudes, as an individual's confidence to enact change increases through awareness and understanding of climate change (Bandura 1977, 1982, 1993).

\section{Climate change education}

A concerted effort to implement educational reforms is necessary to create awareness of the realities of climate change and offers ways to reduce risk and adapt to the dangers that are inevitably forthcoming. Though such initiatives exist in the form of climate change education and education for sustainable development, there is no clear agenda or consensus on best practices (Anderson, 2012). Even though climate change is acknowledged by most, the cause is still often misattributed to the depletion of the ozone layer, signifying a confusion amongst the general public as to the real cause of climate change (Leiserowitz 2007). Enlightening citizens to the true cause of anthropogenic climate change would help raise awareness of the actions and behaviour that could lead to adverse consequences; however, education policy must consider how the message is framed in terms of the motivational outcome that would lead students to adopt environmentally friendly behaviour (Anderson 2013, Smith and Leiserowitz 2014). Offering individual choices and actions that can mitigate climate risk could seem daunting 
and counter to self-efficacy concepts if an individual believes their actions will be offset by the collective actions of others.

Although other nations were also considered, the scope of this research is mainly centred on Australia and China. The former is reported to believe climate change to be a very serious and critical issue at a greater rate amongst the population compared to the latter (Anderson 2013, Stokes, Wike, and Carle 2015). At the governmental level, both countries have highlighted the importance of climate change education to the societal well-being of their countries; however, while Australia remains grid-locked between environment and economy, China has favoured an experimental implementation of educational climate change reforms (Tranter 2014, Han 2015).

Based on the above considerations, the following research questions are sought to be answered through this current research study:

- Is there a discrepancy between self-efficacy and pro-environmental behaviours, particularly between Australian and Chinese students?

- Is there any other socio-demographic factor that might significantly affect an individual's pro-environmental behaviour?

The current study follows in the analysis of environmental attitudes and behaviour applied by Lynn and Longhi (2011) using items from the surveys conducted by the National Centre for Social Research for the Economic and Social Research Council's project 'Understanding Society' (McFall and Garrington 2011). The study looks to determine personal attitudes and behaviours in regards to climate change, specifically with university students from different cultural backgrounds using the relevant questions from ‘Understanding Society' addressed by Lynn and Longhi (2011). It is hypothesised that participants from geographic locations with a greater imminent threat from climate 
change would possess higher self-efficacy, and would show behaviour in accordance with the level of threat their geographic locations face. It is also hypothesised that participants from countries with stronger climate change education policies will show more climate change aware attitudes. In this specific case, China has been chosen as "stronger" in term of policies, as their central government constantly reinforces environmental education into their political agenda, whereas Australian policies require democratic support which is in contention with other ideologies and political entities, and currently only being implemented in the state of New South Wales (Stevenson 2007, Tranter 2014, Han 2015) According to the hypothesis and above considerations, behaviours such as turning off the sink when brushing teeth or switching off the lights in unused rooms, i.e. behaviours that have an economically low impact and are negligible in terms of time commitment, should show correlations with individuals with high self-efficacy from nations that face a more imminent threat from climate change and/or a better climate change education system. This research seeks to advance the understanding of the construct of self-efficacy and how it factors into beliefs and behaviour of students in regards to climate change threats; an area that is curiously neglected in The handbook of environmental education (Stevenson et al. 2013), that the Authors believe to be of particular interest to bridge the gap between beliefs and behaviour.

\section{Methods}

The self-reported behaviour of participants from different countries, in particular Australia and China, was collected and analysed. China represents the geographic location of greater risk within this study, in line with current World Risk Index reports (Garschagen et al. 2016). 


\section{Data Collection}

A representative sample $(n=305)$ of students from Bond University in Australia, aged between 17-59 years, was surveyed. The students' response to which country they have spent more time in throughout their lives, determined whether they would be categorised in the Australian, Chinese or other nationalities' groups. [Insert table 1 here]

The convenience sample consisted of 94 Australians and 64 Chinese participants. The Australian domestic students consisted of 45 males and 49 females. Chinese international students consisted of 22 males and 42 females. While the means were similarly at 24, the Australian students had a greater range of age and were more likely to be employed. Notably Australian participants were mostly in university pursuing their bachelors (68.1\%) while Chinese were pursuing their masters or $\mathrm{PhD}(73.4 \%)$.

A quantitative cross-sectional design was employed to collect data from participants using a self-administered questionnaire. A convenience sample was collected from Bond University students on campus with researcher supervision to clarify any queries by participants.

Participants in the study were asked for information relevant to the research question including information on age, sex, marital status, number of dependent children, education, employment, country of birth, country in which most time was spent, and first language.

Section 2 of the questionnaire employed a 6-point Likert scale to collect information on participants' environmental behaviour towards climate change, respectively. Section 2 collects data from 11 questions on participant behaviour that would influence their personal impact on the environment with $1=\mathrm{n} / \mathrm{a}, 2=$ never, $3=$ not very often, $4=$ quite often, $5=$ very often, and $6=$ always. The response for $\mathrm{n} / \mathrm{a}$ was included 
as some questions such as 'taking public transport instead of car' would not be an option for some students. These measures include low cost, non-time-consuming actions such as turning off the lights or the tap $(\# 14,15)$, energy $(\# 13,14,16)$, water $(\# 15)$, packaging/recycling $(\# 17,18,19)$ and transport $(\# 20,21)$. Though it could be argued that the impact of individual recycling efforts measured in packaging/recycling is minimal in the larger context of global climate change, the measure provides a consumer-oriented environmental measure in buying behaviour. Various measures were included to gather data that encompasses the environmentally related decisions that participants make throughout their daily life.

Section 3 collects data from 16 questions on the participants' attitudes about climate change, particularly on the thought of their actions regarding climate change, their willingness to bear a financial cost for the benefit of the environment, as well as the participants' beliefs about their ability to influence climate change personally and as a nation. Considering that the survey participants were at the university level and assumed to have been previously aware of climate change, a 6-point Likert scale was used to have respondents commit to a positive or negative, with the option of strongly disagree, disagree, somewhat disagree, somewhat agree, agree, and strongly agree and the scale 16 dependent on the questions ( 6 being pro-environmental beliefs/ attitudes, and 1 indicating unfavourable beliefs/ attitudes towards climate change). A critical analysis of how participants answered questions relating to self-efficacy was conducted to estimate the effects of self-efficacy in determining motivation of pro-environmental behaviour. To do this, 8 questions (survey question $\# 24,25,26,28,29,34,35,37$ ) from the attitudes section of the survey were chosen under the parameter 'individual's perceived capability to enact change', in regard to pro-environmental behaviour towards climate change. The items were chosen following Bandura (2006) "Guide for constructing self-efficacy 
scales" and focused on the individual's perception towards their ability to change behaviour, despite the complexity and magnitude of the global climate, which allows the self-efficacy construct of this study to be free from co-variables such as self-esteem, locus of control, and outcomes expectancies.

\section{Statistical Analysis}

Collected data was compiled for analysis through IBM's Statistical Package for the Social Sciences (SPSS) to analyse the relation between attitudes and behaviour.

Cronbach's alpha was measured for internal reliability of survey questions for behaviour, attitude, and self-efficacy across the entire sample, the Chinese sample, and Australian sample.

An independent samples t-test was used to analyse the difference between attitudes and self-reported behaviours of participants who have spent a greater amount of time in Australia compared to China. Analysis was carried out between the two groups in terms of Total Self-efficacy score, Low-cost-low-time-consuming behaviour, an aggregate total of environmentally friendly behaviour, an aggregate total of environmentally friendly attitudes/ beliefs, and subtotals based on the behaviour aggregate split by their relation to i) water consumption, ii) energy consumption, iii) use of recycled material and packaging, and iv) transport behaviour.

A Pearson's correlation analysis was conducted to assess the relation between self-efficacy and the six environmentally friendly behaviour variables used above: lowcost-low-time-consuming behaviour, aggregate total of environmentally friendly behaviour, and subtotals based on environmental behaviour split by their relation to i) water consumption, ii) energy consumption, iii) use of recycled material and packaging, and iv) transport behaviour. 


\section{Bayesian network development}

Bayesian Networks (BN) can be defined as probabilistic, directed acyclic graphs. They rely on the application of the Bayes' theorem, which is used for inferring or updating the amount of 'belief' when new information is provided. In a BN, variables (or nodes) are connected by arcs, usually based on a prior understanding of the system to be modelled. The relationships between such nodes are numerically quantified through conditional probability tables (CPTs). A CPT is developed in order to display the conditional probability of a single variable with respect to the other(s) (e.g. what is the probability that my backyard is wet given that it rained this morning?) which can be populated either based on available data or qualitatively through experts' or stakeholders' input. More details on different components of a $\mathrm{BN}$ and how to build one can be found in e.g. Fenton and Neil (2013). BN can be applied to model systems or datasets with limited information or high uncertainty (Uusitalo 2007, Chen and Pollino 2012) and represent a promising tool to reveal complex associations among disparate data types, including questionnaires (Noyes et al. 2018). They have been applied in several different fields of research, including water resources management (Bertone et al. 2016), education (Xenos 2004, García et al. 2007, Fernández et al. 2011), and climate change - related beliefs (Cook and Lewandowsky 2016), and they can deal with non-normal, non-linear data, outliers, and small sample sizes, unlike a number of traditional statistical methods such as structural equation modelling (Mondiana, Pramoedyo, and Sumarminingsih 2018).

To complement the traditional statistical data analysis, a naïve $\mathrm{BN}$ was developed and populated with the data from the questionnaire, including socio-demographic information. In a naïve BN, one parent node (which in this case is also the target variable) is connected to several child nodes, and does not depend on any other nodes. Essentially, 
in this way all the potential predictors (i.e. child nodes) are equally considered, rather than assuming some specific relationships among variables such as with structural equation modelling. The downside is that, among the different feature nodes, no interdependency is assumed. They are thus regarded as conditionally independent, hence the definition of 'naive'. Because of this limitation, in order to ensure that the conditional independence assumption is valid for all the child nodes, a self-organising map (SOM) was developed to concurrently check for significant correlations amongst these several variables. SOMs are a type of artificial neural network performing dimensionality reduction (Kohonen 1998), effectively enabling to visually cluster correlated variables. This is because a SOM is composed of a number (one per variable) of topologically ordered colour maps: similar colour patterns among them would imply a correlation. This visual exploration represents a rapid and intuitive approach for identification of multiple inter-parameter relationships; unlike other analysis approaches, SOM allows for, for instance, nonlinear relationships to be detected. A SOM was developed using the SOM toolbox (Vesanto 2000), in Matlab R2018a 64 bit (The Mathworks, Inc.).

The developed naïve BN structure is illustrated in Figure 1. Blue nodes represent survey-related variables; the centre node is the only parent node, which is also the focus of the BN, i.e. self-efficacy; while the green nodes are socio-demographic information of the survey participants. For those initially continuous variables (e.g. age), the node was discretised in a number of states (maximum 5) with intervals based on the data features, for optimal population of the CPTs. The aim of this BN was to identify potential to understand how self-efficacy relates to certain socio-demographic and other calculated features of the students participating in the survey. [insert figure 1 here]. As explained above, SOM was used in conjunction with the BN to ensure these child nodes are not 
interrelated and that in turn each individual relationship extracted from the $\mathrm{BN}$ is unique and not affected by other confounding factors.

\section{Results}

\section{Statistical analysis results}

The internal reliability of self-efficacy and attitude are adequate, with correlation coefficients above 0.70 for interrelatedness. The behaviour measures scored slightly below 0.70 overall and slightly below 0.60 for the Chinese sample, likely due to the nature of the behavioural construct of the questionnaire comprising of questions relating to various sub-categories of pro-environmental behaviour (i.e. transport, water, energy) [Insert table 2 here]

Despite no significant difference in attitude toward climate change, the selfreported behaviour of Australian students indicate that they are less environmentally friendly compared to the Chinese sample students. The analysis in Table 3 shows the selfreported behaviour to be in line with the hypothesized result, with Chinese proenvironmental behaviour reportedly higher. Further, the table shows that analysis yielded a slightly more pro-environmental stance for all sub categories under behaviour, with people that spent a longer time in China reporting their behaviour to be more environmentally friendly, regarding reduced energy consumption, reduced packaging consumption, and reduced fuel consumption. The aggregate score on climate change attitudes showed no significant difference compared to results from Leiserowitz (2007), whose report indicated a significantly greater climate change concern in Australia. [insert table 3 here] 
Table 4 shows Pearson correlations between the self-efficacy score and other variables that were analysed in the study. The hypothesis stated that self-efficacy would be a determining factor affecting the behavioural outcome, particularly for behaviours impacting the environment positively but having a low cost and low time-commitment to the individual. The Pearson's correlation analysis outputs show a low-moderate correlation with the hypothesized effect, slightly lower than the correlation between low cost behaviour and overall attitude. [insert table 4 here]

The analysis between the self-efficacy measure of Australia and China showed little difference, with the sample from China having a slightly higher score. To understand the potential for self-efficacy to influence behaviour, and due to the lack of difference between Australia and China, further measures were analysed to find any potential relation between self-efficacy and self-reported behaviour throughout the entire sample population.

The Pearson's correlation between the total environmentally-friendly behaviour score and total environmentally-friendly beliefs score was low-moderate. Despite the hypothesis that low-cost low-time consuming environmentally-friendly behaviour would yield higher environmentally-friendly scores relative to high-cost ones, the correlation between self-efficacy and low-cost-low-time-consuming behaviour was weak compared to the moderate correlation between self-efficacy and overall environmentally-friendly behaviour. The assumption that low-cost low-time-consuming behaviour would relate to a greater score compared to overall-behaviour was made to reflect the fact that financial barriers, namely the difference between domestic and international students, may limit an individual's ability to align their behaviour with their beliefs. However, the correlation and t-tests show that overall there was no difference between Australia and China. The self-efficacy correlation, on the other hand, show that Australians with higher self- 
efficacy are more likely to exhibit pro-environmental behaviour in the sub-categories of packaging and transport (moderate correlation), compared to Chinese and the overall sample which showed a weak correlation. This could be due to the fact that local Australians may have greater options for transport (i.e. car ownership) or may have more leeway in purchasing environmentally friendly products as international students may be more likely to be cost conscious (i.e. buying furniture/ appliances for a new rental flat). [Insert table 5 here]

It could be that self-efficacy may be a significant predictor in pro-environmental behaviour even if there is financial or time loss in order to align behaviour with attitudes (Bandura 1993). The difference between Australia and China's Pearson's correlation for self-efficacy (Table 4) for the factors behaviour, energy, packaging, and transport is less compared to attitude (Table 5). The Pearson's correlation between overall attitude and self-efficacy was high $(>0.8)$, indicating that the self-efficacy score, which consisted of an aggregate score of 8 items out of the 16 overall environmentally-friendly attitudes items, may have predictive potential in determining an individual's overall climate change attitudes. While education to increase the student's explicit knowledge on climate change seems paramount to instigate behavioural changes, self-efficacy seems to be a necessary and useful measure to integrate into the educational curriculum.

\section{Bayesian Network results}

The $\mathrm{BN}$ focused more on the socio-demographic aspects of the participants and how these relate to self-efficacy. Firstly, the SOM (Fig. 2) was developed. It can be noticed that the colour pattern of the target variable (i.e. self-efficacy) is rather different from all the potential inputs (e.g. socio-demographic variables), meaning that no individual parameter (and most likely not all the collected ones together) can explain the 
self-efficacy score on its own. Expected similar patterns can be noticed between e.g. Total_S2_Behaviour and the different S2 sub-factors, since the former is a numerical combination of the latter. Importantly, different patterns were noticed between all the socio-demographic parameters. This is crucial for the naïve BN analysis: if for instance, the BN found a correlation between self-efficacy and country, based on SOM analysis it would be possible to state that it is a true correlation, and not the by-product of underlying confounding factors (e.g. education being substantially different based on country, thus education being the real predictor). [insert figure 2 here]

Based on the BN model and its CPTs, Figures 3 and 4 show how the probability of a student having certain features increase (Fig. 3) or decrease (Fig. 4) with higher selfefficacy scores. It can be noticed how:

- The probability of a student being a male increases with self-efficacy, while it decreases for females, highlighting how males seem to have higher selfefficacy than females.

- $\quad$ Older people have a higher probability of having high self-efficacy.

- The probability of a participant being a manager or a professional, or having at least a Master's degree, increases with higher self-efficacy; the probability of a participant having completed only high school, or being employed on a causal basis, decreases with higher self-efficacy instead. This shows a clear relationship between level of education and employment and self-efficacy.

- Participants with 3 dependent children have a higher chance of low selfefficacy.

- Students who spent most of their time in China are more likely to have a high self-efficacy score, while for students who spent most of their time in Australia, there is no clear trend. [insert figure 3 and 4 here] 
Besides these specific outputs, the BN allows the user to enter a specific set of sociodemographic information of a particular student, and estimate the student-specific likelihood of different self-efficacy levels, based on the conditional probabilities derived from the surveys of this study.

\section{Discussion}

The implementation of climate change policy to cause change in individual behaviour demands a better understanding of the disparity between the risk perception associated with geographic location and environmentally conscious behaviour (Kim and Wolinsky-Nahmias 2014). Those that experience a climate-related disaster may overattribute it to climate change, while others may perceive climate change to be geographically distant and outside of their individual concern (Swim et al. 2009, Van der Sluijs 2012). Interestingly, the issue of rising temperatures remains controversial despite a global trend of concern for environmental issues; industrialised nations perceive the risk associated with rising temperatures to be less than developing countries (Marquart-Pyatt 2015). This problem is further compounded by climate change accelerating outside of the range that has been experienced throughout human history, hindering the planning efforts of individuals and organisations due to the lack of information and evidence to reliably predict the extent of climate disasters in the future (Swim et al. 2009).

Geographic location is a logical factor in determining the risk that an individual, organisation, or nation may attribute to climate change, but it is not necessarily what determines environmental behaviour. In terms of awareness and perception of human cause, a nation's wealth and education are greater indicators (Knight 2016). To promote sustainable behaviour, research has shown that appealing to emotions while developing a nation's climate policy, through i.e. marketing/ advertising efforts, can affect the climate 
change beliefs of individuals (Semenza et al. 2008, Hall and Allan 2014, Howell 2014, Kim and Wolinsky-Nahmias 2014). While the results of the current study demonstrate that beliefs hold significant influence on individual climate change behaviour, the connection between how beliefs turn into behaviour remains unclear.

The study compared the self-reported behaviour and beliefs of those that have spent a majority of their time in Australia or China. Assuming no mitigation efforts, it is estimated that China will lose $12 \%$ annually in total manufacturing output by 2050 due to higher temperatures (Zhang et al. 2017). Australia would face similar changes in temperature, according to Pachauri et al. (2014); however, China is considered to be the country associated with greater vulnerability and risk to natural disasters according to the World Risk Index report due to the susceptibility of the national infrastructure and issues of adaptability for the large and relatively poorer population (Garschagen et al. 2016). Despite this, Australia is considered to have a slightly greater exposure to climate risks according to the World Risk Index report; it is a relatively hotter country with more desert areas and less geographic diversity compared to China. A majority of the population and infrastructure is located along the coast, exposed to sea level rise risks. Australia is also expected to become drier, which will increase the already large amount of arid land, particularly in interior regions (Pachauri et al. 2014). If the hypothesis was correct, results would have indicated that the self-reported sustainable behaviour would be more prevalent in Australia, which is also reported to have a greater concern for climate change (Leiserowitz 2007). However, the analysis showed no significant differences in climate change beliefs nor in low-cost low-time-consuming environmentally friendly behaviour. China attained a higher score in overall measures of self-reported environmentallyfriendly behaviour, particularly in those relating to the economic use of electricity. Despite having over a 25-year history of attempts in educating and implementing 
sustainable development, and having a population that is generally more concerned about climate risks, it seems the Australian governments' awareness of climate risk has not translated into behaviour at the individual level, at least when compared to the more recent Chinese policies that has placed top-down pressure for change (Leiserowitz 2007, Curran and Hollander 2015, Han 2015).

In spite of being a significant contributor to climate change, China has taken a stance of leading through action rather than forcing other nations in binding agreements on carbon emissions (He 2010, Dai et al. 2016). Despite the efforts, however, the relation between economic prosperity and sustainable development presents issues for all nations as the narrative of competing for wealth equating to success is fundamentally counter to cooperating to conserve the environment; at the individual level, this is further reinforced by education programs that often prioritise students' test performance over environmental education (Witoszek 2018). A study by Sternäng and Lundholm (2011) at institutes explicitly focusing on environmental education highlights a confluence of these issues, where researchers had to convince the students being interviewed that they were not being assessed, as students seemed to be providing 'ethically correct' answers in line with their school. Interestingly, as students began to express their personal opinions, researchers were able to identify that moral reasoning of environmental problems differed between students' opinion of 'what individuals in society should do' and 'what the student would choose to do' when faced with a socio-ethical dilemma. Educational efforts on sustainable development have only recently been implemented through environmental policy; however, the survey results of this study show that the efforts of the Chinese government to enact individual pro-environmental behaviour may be effective, albeit difficult to discriminate between students' moral reasoning or actual individual behaviour (Han 2015). 
The lack of action being taken to insulate or mitigate risks associated with climate change from a policy and educational perspective is a worrisome trend. It is well-known that with proper organisation and a concerted effort, economic benefits would be achievable through the implementation of appropriate sustainable, environmentalfriendly policies and city planning (Hunt and Watkiss 2011, Bertone et al. 2018). However, it could be that wealthier nations, while being aware of the ongoing and future risk of climate change, are blinded by their economic prosperity and collectively believe that they are better equipped to deal with climate-related disasters as they become more prevalent in the future (Lo and Chow 2015). Notably, in the comparison of China and Australia by the World Risk Report, Australia is considered the safer region, more adaptable to disasters due to its economy and infrastructure despite having a slightly higher exposure to climate risks (Garschagen et al. 2016). Perhaps the perception of safety created by societal safeguards causes individuals of those nations to feel secure without taking more individual steps to promote environmental behaviour despite showing concern for the environment. Furthermore, the lack of action, in the face of overwhelming evidence, could largely be attributed to the uncertain nature of the future, particularly when dealing with abstract ideas such as the many variables influencing climate change (Moisander 2007, Marx et al. 2007, Van der Sluijs 2012). Many call for an emotional appeal to the global population in order to raise awareness and concern to commence the mitigation of risk at the individual level as soon as possible (Ockwell, Whitmarsh, and O'Neill 2009, Panno et al. 2015, Marx et al. 2007). However, care must be taken as instigating a strong emotion of fear has been known to cause the public to feel overwhelmed and disengage with the issue of climate change, while appealing to the emotion of worry could be useful to communicators promoting a constructive analytical approach that would be required to deal with the long-term complexities of the future 
climate (Smith and Leiserowitz 2014). A more holistic understanding of how beliefs and attitudes eventuate into behaviour would be beneficial in targeting specific behaviour changes through suitable educational policies that are sensitive to regional differences and individual concerns. Policy focusing on relaying examples of pro-environmental behaviour and connecting individuals with like-minded groups could lead to a greater ability to take collective action (Moisander 2007, Howell 2014, Marx et al. 2007).

When considering policy, governments must show a significant effort to educate citizens to a sustainable future that takes climate change into consideration. Although individual change is necessary to mitigate climate change, a significant part of policy is dictated by political and corporate interests, and with no clear solutions in sight, their best interests may not lie in bearing the cost of mitigation (Kim and Wolinsky-Nahmias 2014). While better educated citizens are generally more aware of the issues surrounding climate change, the knowledge and awareness of climate change must be reinforced with actionable behaviour that aligns pro-environmental behaviour with the publics beliefs (Han 2015, Tranter 2014). It could be that the behaviour of the Australians, showing less pro-environmental actions than Chinese, is linked to the political gridlock seen in many democratic countries (Antonio and Brulle 2011, Curran and Hollander 2015), while the Chinese government, which owns its major industries, does not have to politically compete with itself to prioritise environment over economy (He 2010). China is, by far, a greater polluter due to its sheer demand for energy consumption, however, the disparity between the results showing more self-reported pro-environmental behaviour in this study, while pro-environmental attitudes showed no significant differences, is in contrary to other studies such as Stokes, Wike, and Carle (2015), who found that Australia showed both greater concern and willingness to limit greenhouse gas emissions compared to China. 
The Bayesian network was used to analyse any further differences that could be statistically derived from the samples. The focus was placed on self-efficacy, which provided a greater indicator of behaviour in the Chinese sample, as well as the overall sample when compared to attitude despite self-efficacy being derived from half of the total attitude items (Australians had a higher correlation of attitude and behaviour when compared to the correlation of self-efficacy and behaviour). Mirroring this fact, the $\mathrm{BN}$ showed that high self-efficacy was more probable for the students of the Chinese sample, while there was no clear trend for the Australians, whose attitudes were more in line with their behaviour compared to self-efficacy. Despite not being a greater indicator for the Australians, self-efficacy maintained a relatively strong correlation while being economical in the number of questions asked to participants, which warranted a further investigation as to sociodemographic factors that may influence this measure. As a measure that reflects an individual's perceived capability to positively affect climate change, the fact that participants' actual ability to affect climate change, measured here in self-reported behaviour could be influenced by honing self-efficacy in individuals through education, in line with a study by Lauren et al. (2016) that correlated self-efficacy and its development as a tool in increasing pro-environmental behaviour. Another study by Meinhold and Malkus (2005), also showed that self-efficacy correlates strongly with behaviour in adolescent groups, though their self-efficacy measure was general rather than specific towards the environment. Their data suggested that self-efficacy's relation to behaviour may be an independent variable for males, while being a moderating variable for females. While being of a different age group, the $\mathrm{BN}$ in our study indicated the contrary, i.e. that participants with higher self-efficacy were more likely to be male. Interestingly, girls throughout obligatory school (up to the age of 15), are known to agree with sentiments of pro-environmental attitudes, concern for climate change, and a belief 
that individual changes can influence the environment (Sjøberg and Schreiner 2010). Though it would be interesting to see how self-efficacy changes throughout a larger range of ages, the BN prediction of self-efficacy in the limited age range of our sample in our study indicates that the 17-21 year-olds is neutral, 25-28 as slightly inverse, and 28+ as positive, suggesting that participants perceived ability to impact climate change fluctuates throughout their life.

Perhaps, more important than self-efficacy as a function of age, is to empower the self-efficacy of the future generations that will ultimately bear the cost of mitigating climate change. Fortunately, young people from high polluting countries strongly support limiting emissions compared to their seniors (Stokes, Wike, and Carle 2015). However, if students experience repeated failure and a lack of ability to enact pro-environmental efforts, individually and as a society, then according to Bandura (1982) self-efficacy would diminish during the critical phase throughout the early education cycles of students.

Despite the many uncertainties, there remains hope in educational reforms that could create citizens with a greater willingness and ability to cope with climate change. Educational institutions have clearly increased the focus on climate change awareness (Semenza et al. 2008, Ockwell, Whitmarsh, and O'Neill 2009, Lynn and Longhi 2011, Longhi 2013, Howell 2014, Lo and Chow 2015). However, research suggests that students must be made aware of specific behavioural changes to achieve the desired outcomes, as well as develop a problem-solving mentality to deal with the complex uncertainties that climate problems exhibit (Pruneau et al. 2003, Anderson 2013, Birkmann and Welle 2016). Of critical importance is "educating the educators", to make them capable of dealing with the task; though not necessarily time-consuming, policy must address the issue in order to transfer the behavioural outcomes to their students 
(Anderson 2013, Witoszek 2018). Additionally, other outputs of the BN can provide important insights for policy-makers; for instance, because self-efficacy "naturally" increases with the level of education, Australian and Chinese governments should focus their efforts on climate change education programs implementation at early stages of the students' learning journey, such as in high school.

\section{Research Limitations}

Despite the best efforts to conduct a survey, ultimately the behaviour of participants are self-reported and may be influenced by bias, where participants may feel inclined to report the ethically correct answer for both behaviour and attitudes. Due to being a convenience sample, there may be sample bias, such as certain faculties and programs that study in remote areas of the campus may be under represented. Furthermore, the study was conducted in a private university and the results may not be generalizable to public universities or the public in general.

Though the study was systematically analysing the difference between Australian and Chinese students, there could be other factors that influence the differences that were not measured. Australia and China are vast countries and the participants' home location within their country may influence their beliefs about the environment, which the surveys could include in future iterations and with larger sample size.

The survey, though attempting to find a broad measure of environmental behaviour, was comprised of multiple subcategories that would require further questions to improve reliability. Future research should look at these individual constructs separately as the aggregated totals do not consider that different categories have inherently different time and economical costs. 
BN, combined with SOM, proved to be a very effective tool to extract patterns in questionnaire data; future work should seek to collect a larger dataset, in order to move away from a naïve BN structure and from the assumption of conditional independency among potentially correlated nodes. In this particular study, SOM revealed no correlation among the child nodes of the naïve $\mathrm{BN}$, allowing the conditional independence assumption to be valid. However, if SOM analysis revealed correlations among some of them (e.g. age and education), then a naïve BN would not have been able to separate the individual influence that each of them would have on the target variable (e.g. selfefficacy). In this case, the only solution would be the collection of a larger dataset and the construction of a traditional BN.

Future research should also analyse and seek to further understand psychological and cultural factors that influence the behaviours of individuals. The relation between incurring personal loss and self-efficacy in order to achieve climate change goals must be further explored. Factors such as cultural identity, and the beliefs associated with different cultures, such as collectivism and individualism should be incorporated into the behavioural outcomes in the context of climate-change behaviour.

\section{Conclusion}

Though prevailing beliefs tend to support climate change mitigation, there is still disparity between personal belief and practical behaviour both at an individual and organisational level. In order to assess the role played by the physical threat posed by climate change, as well as the effectiveness of climate change educational policies, behavioural data was collected and analysed from a number of university students from China and Australia. The survey showed that Chinese students reported having behaviour that was more in line with their climate change attitudes and self-efficacy, despite having 
similar climate change attitudes and self-efficacy scores when compared to Australian students. Self-efficacy was found to be a predictor of pro-environmental behaviour while being comprised of half the questions from attitudes, and in the sample, was a greater predictor than attitudes score for the entire sample and for China. In addition, self-efficacy was correlated with socio-demographic features of the participants (e.g. age, level of education, gender) with a Bayesian Network. Although limitations to this study exist, these findings seem to support that climate change educational policies in China have been more effective in changing learners' behaviours. Thus, efforts to inform and empower students could result in long-term collective behavioural changes that may lead to remarkable economic benefits and effectively help mitigate and adapt to climate change. Future studies could analyse the Chinese education system's efforts to implement sustainable development in their curriculum and determine effective practices that could be generalised to educate a wider range of students about climate change. 


\section{References}

Anderson, Allison. 2013. "Climate change education for mitigation and adaptation." Journal of Education for Sustainable Development 6 (2):191-206. doi: https://doi.org/10.1177/0973408212475199.

Antonio, Robert J, and Robert J Brulle. 2011. "The unbearable lightness of politics: climate change denial and political polarization." The Sociological Quarterly 52 (2):195-202.

Bandura, Albert. 1977. "Self-efficacy: toward a unifying theory of behavioral change." Psychological review 84 (2):24. doi: http://dx.doi.org/10.1037/0033295X.84.2.191.

Bandura, Albert. 1982. "Self-efficacy mechanism in human agency." American psychologist 37 (2): 122.

Bandura, Albert. 1993. "Perceived self-efficacy in cognitive development and functioning." Educational psychologist 28 (2):117-148.

Bandura, Albert. 2006. "Guide for constructing self-efficacy scales." In Self-efficacy beliefs of adolescents, 307-337. Connecticut, USA: Information Age.

Bertone, Edoardo, Oz Sahin, Russell Richards, and Anne Roiko. 2016. "Extreme events, water quality and health: A participatory Bayesian risk assessment tool for managers of reservoirs." Journal of Cleaner Production 135:657-667. doi: http://dx.doi.org/10.1016/i.jclepro.2016.06.158.

Bertone, Edoardo, Oz Sahin, Rodney A Stewart, Patrick XW Zou, Morshed Alam, Keith Hampson, and Evan Blair. 2018. "Role of financial mechanisms for accelerating the rate of water and energy efficiency retrofits in Australian public buildings: Hybrid Bayesian Network and System Dynamics modelling approach." Applied Energy 210:409-419.

Birkmann, Joern, and Torsten Welle. 2016. "The WorldRiskIndex 2016: Reveals the necessity for regional cooperation in vulnerability reduction." Journal of Extreme Events 3 (02):21.

Carleton, Tamma A, and Solomon M Hsiang. 2016. "Social and economic impacts of climate." Science 353 (6304):aad9837.

Change, Intergovernmental Panel on Climate. 2014. Climate Change 2014. In Fifth Assessment Report (AR5). Geneva: IPCC.

Chen, SH , and CA Pollino. 2012. "Good practice in Bayesian network modelling." Environmental Modelling \& Software 37:134-145.

Cook, John, and Stephan Lewandowsky. 2016. "Rational irrationality: Modeling climate change belief polarization using Bayesian networks." Topics in cognitive science 8 (1):160-179.

Coutenay-Hall, Pamela, and Larson Rogers. 2002. "Gaps in mind: Problems in environmental knowledge-behaviour modelling research." Environmental Education Research 8 (3):283-297. doi: https://doi.org/10.1080/13504620220145438.

Curran, Giorel, and Robyn Hollander. 2015. 25 years of Ecologically Sustainable Development in Australia: paradigm shift or business as usual? : Taylor \& Francis. 
Dai, Hancheng, Xuxuan Xie, Yang Xie, Jian Liu, and Toshihiko Masui. 2016. "Green growth: The economic impacts of large-scale renewable energy development in China." Applied energy 162:435-449.

Dasgupta, Partha. 2008. "Discounting climate change." Journal of risk and uncertainty 37 (2-3):141-169.

Fenton, N., and M. Neil. 2013. Risk Assessment and Decision analysis with Bayesian Networks. New York: CRC Press.

Fernández, Antonio, María Morales, Carmelo Rodríguez, and Antonio Salmerón. 2011. "A system for relevance analysis of performance indicators in higher education using Bayesian networks." Knowledge and information systems 27 (3):327-344.

García, Patricio, Analía Amandi, Silvia Schiaffino, and Marcelo Campo. 2007. "Evaluating Bayesian networks' precision for detecting students' learning styles." Computers \& Education 49 (3):794-808. doi: https://doi.org/10.1016/j.compedu.2005.11.017.

Garschagen, Matthias, Michael Hagenlocher, Martina Comes, Mirjam Dubbert, Robert Sabelfeld, Yew Jin Lee, Ludwig Grunewald, Matthias Lanzendörfer, Peter Mucke, and Oliver Neuschäfer. 2016. World risk report 2016. In World Risk Report. Berlin.

Hall, Clare, and Fraser Allan. 2014. "Influencing Carbon Behaviours: What Psychological and Demographic Factors Contribute to Individual Differences in Home Energy Use Reduction and Transportation Mode Decisions?" Energy and Environment Research 4 (1):1.

Han, Qingqing. 2015. "Education for sustainable development and climate change education in China: A status report." Journal of Education for Sustainable Development 9 (1):62-77.

Harring, Niklas, and Sverker C Jagers. 2018. "Why do people accept environmental policies? The prospects of higher education and changes in norms, beliefs and policy preferences." Environmental Education Research 24 (6):791-806. doi: https://doi.org/10.1080/13504622.2017.1343281.

He, Lichao. 2010. "China's climate-change policy from Kyoto to Copenhagen: domestic needs and international aspirations." Asian Perspective 34 (3):5-33.

Heimlich, JE, P Mony, and V Yocco. 2014. "Belief to behavior: A Vital Link." In International handbook of research on environmental education, edited by $\mathrm{R}$. Stevenson, Brody, M., Dillon, J., \& Wals, A., 262-274. London: Taylor \& Francis.

Hines, Jody M, Harold R Hungerford, and Audrey N Tomera. 1986/87. "Analysis and synthesis of research on responsible environmental behavior: A meta-analysis." Journal of environmental education 18 (2):1-8. doi: https://doi.org/10.1080/00958964.1987.9943482.

Howell, Rachel A. 2014. "Investigating the long-term impacts of climate change communications on individuals' attitudes and behavior." Environment and Behavior 46 (1):70-101.

Hungerford, Harold R, and Trudi L Volk. 1990. "Changing learner behavior through environmental education." The journal of environmental education 21 (3):8-21. doi: https://doi.org/10.1080/00958964.1990.10753743.

Hunt, Alistair, and Paul Watkiss. 2011. "Climate change impacts and adaptation in cities: a review of the literature." Climatic Change 104 (1):13-49.

Kim, So Young, and Yael Wolinsky-Nahmias. 2014. "Cross-national public opinion on climate change: The effects of affluence and vulnerability." Global Environmental Politics 14 (1):79-106. 
Knight, Kyle W. 2016. "Public awareness and perception of climate change: a quantitative cross-national study." Environmental Sociology 2 (1):101-113. doi: https://doi.org/10.1080/23251042.2015.1128055.

Kohonen, Teuvo. 1998. "The self-organizing map." Neurocomputing 21 (1):1-6.

Lauren, Nita, Kelly S Fielding, Liam Smith, and Winnifred R Louis. 2016. "You did, so you can and you will: Self-efficacy as a mediator of spillover from easy to more difficult pro-environmental behaviour." Journal of Environmental Psychology 48:191-199. doi: https://doi.org/10.1016/j.jenvp.2016.10.004.

Leiserowitz, Anthony. 2007. International public opinion, perception, and understanding of global climate change. In Human development report 2007/2008.

Lo, Alex Y, and Alex T Chow. 2015. "The relationship between climate change concern and national wealth." Climatic change 131 (2):335-348.

Longhi, Simonetta. 2013. Individual pro-environmental behaviour in the household context. In ISER Working Paper Series 2013-21. Colchester: University of Essex.

Lynn, Peter, and Simonetta Longhi. 2011. Environmental attitudes and behaviour: who cares about climate change? In Understanding Society, edited by Stephanie L \& Garrington McFall, C. Colchester: Institute for Social and Economic Research.

Marquart-Pyatt, Sandra T. 2015. "Public Opinion about the Environment: Testing Measurement Equivalence across Countries." International Journal of Sociology 45 (4):309-326. doi: https://doi.org/10.1080/00207659.2015.1098268.

Marx, Sabine M, Elke U Weber, Benjamin S Orlove, Anthony Leiserowitz, David H Krantz, Carla Roncoli, and Jennifer Phillips. 2007. "Communication and mental processes: Experiential and analytic processing of uncertain climate information." Global Environmental Change 17 (1):47-58.

McFall, Stephanie L, and Chris Garrington. 2011. Understanding society: early findings from the first wave of the UK's Household Longitudinal Study. Colchester: University of Essex: Institute for Social and Economic Research.

Meinhold, Jana L, and Amy J Malkus. 2005. "Adolescent environmental behaviors: Can knowledge, attitudes, and self-efficacy make a difference?" Environment and behavior 37 (4):511-532. doi: https://doi.org/10.1177/0013916504269665.

Mochizuki, Yoko, and Audrey Bryan. 2015. "Climate change education in the context of education for sustainable development: Rationale and principles." Journal of Education for Sustainable Development 9 (1):4-26.

Moisander, Johanna. 2007. "Motivational complexity of green consumerism." International journal of consumer studies 31 (4):404-409.

Mondiana, Yani Quarta, Henny Pramoedyo, and Eni Sumarminingsih. 2018. "Structural Equation Modeling on Likert Scale Data With Transformation by Successive Interval Method and With No Transformation." International Journal of Scientific and Research Publications (IJSRP) 8(5) (ISSN: 2250-3153) http://dx.doi.org/10.29322/IJSRP.8.5.2018.p7751.

Noyes, Noelle, Kyu-Chul Cho, Jacques Ravel, Larry J Forney, and Zaid Abdo. 2018. "Associations between sexual habits, menstrual hygiene practices, demographics and the vaginal microbiome as revealed by Bayesian network analysis." PloS one 13 (1): $\mathrm{e} 0191625$.

Ockwell, David, Lorraine Whitmarsh, and Saffron O'Neill. 2009. "Reorienting climate change communication for effective mitigation: forcing people to be green or fostering grass-roots engagement?" Science Communication 30 (3):305-327.

Pachauri, Rajendra K, Myles R Allen, Vicente R Barros, John Broome, Wolfgang Cramer, Renate Christ, John A Church, Leon Clarke, Qin Dahe, and Purnamita 
Dasgupta. 2014. Climate change 2014: synthesis report. Contribution of Working Groups I, II and III to the fifth assessment report of the Intergovernmental Panel on Climate Change: IPCC.

Panno, Angelo, Giuseppe Carrus, Fridanna Maricchiolo, and Lucia Mannetti. 2015. "Cognitive reappraisal and pro-environmental behavior: The role of global climate change perception." European Journal of Social Psychology 45 (7):858867.

Pruneau, Diane, Helene Gravel, Wendy Bourque, and Joanne Langis. 2003. "Experimentation with a socio-constructivist process for climate change education." Environmental Education Research 9 (4):429-446.

Santer, Benjamin D, KE Taylor, TML Wigley, and TC Johns. 1996. "A search for human influences on the thermal structure of the atmosphere." Nature 382 (6586):39.

Semenza, Jan C, David E Hall, Daniel J Wilson, Brian D Bontempo, David J Sailor, and Linda A George. 2008. "Public perception of climate change: voluntary mitigation and barriers to behavior change." American journal of preventive medicine 35 (5):479-487.

Shove, Elizabeth. 2010. "Beyond the ABC: climate change policy and theories of social change." Environment and planning A: Economy and Space 42 (6):1273-1285. doi: https://doi.org/10.1068/a42282.

Sjøberg, Svein, and Camilla Schreiner. 2010. "The ROSE project: An overview and key findings." Oslo: University of Oslo:1-31.

Smith, Nicholas, and Anthony Leiserowitz. 2014. "The role of emotion in global warming policy support and opposition." Risk Analysis 34 (5):937-948. doi: https://doi.org/10.1111/risa.12140.

Sternäng, Li, and Cecilia Lundholm. 2011. "Climate change and morality: Students' perspectives on the individual and society." International Journal of Science Education 33 (8):1131-1148. doi: https://doi.org/10.1080/09500693.2010.503765.

Stevenson, Robert B. 2007. "Schooling and environmental education: Contradictions in purpose and practice." Environmental Education Research 13 (2):139-153. doi: https://doi.org/10.1080/13504620701295726.

Stevenson, Robert B, Michael Brody, Justin Dillon, and Arjen EJ Wals. 2013. International handbook of research on environmental education. New York: Routledge.

Stokes, Bruce, Richard Wike, and Jill Carle. 2015. Global concern about climate change, broad support for limiting emissions. Pew Research Center.[ARP].

Swim, Janet, Susan Clayton, Thomas Doherty, Robert Gifford, George Howard, Joseph Reser, Paul Stern, and Elke Weber. 2009. Psychology and global climate change: Addressing a multi-faceted phenomenon and set of challenges. In $A$ report by the American Psychological Association's task force on the interface between psychology and global climate change: American Psychological Association.

Tikir, Aysel, and Bernard Lehmann. 2011. "Climate change, theory of planned behavior and values: A structural equation model with mediation analysis." Climatic change 104 (2):389-402.

Tranter, Bruce. 2014. "Social and political influences on environmentalism in Australia." Journal of Sociology 50 (3):331-348.

UNESCO. 2015. Not Just Hot Air: Putting Climate Change Education into Practice. 7, place de Fontenoy, 75352 Paris 07 SP, France: United Nations Educational, Scientific and Cultural Organization. 
UNESCO. 2016. Education for people and planet: Creating sustainable futures for all. 7 , Place de Fontenoy, 75352 Paris 07 SP, France United Nations Educational, Scientific and Cultural Organization.

Uusitalo, L. 2007. "Advantages and challenges of Bayesian networks in environmental modelling." Ecological Modelling 203:312-318.

Van der Sluijs, Jeroen P. 2012. "Uncertainty and dissent in climate risk assessment: A post-normal perspective." Nature and culture 7 (2):174-195.

Vesanto, Juha. 2000. "Neural network tool for data mining: SOM toolbox." Proceedings of symposium on tool environments and development methods for intelligent systems (TOOLMET2000).

Vitousek, Peter M, Harold A Mooney, Jane Lubchenco, and Jerry M Melillo. 1997. "Human domination of Earth's ecosystems." Science 277 (5325):494-499.

Witoszek, Nina. 2018. "Teaching sustainability in Norway, China and Ghana: challenges to the UN programme." Environmental Education Research 24 (6):831-844. doi: https://doi.org/10.1080/13504622.2017.1307944.

Xenos, Michalis. 2004. "Prediction and assessment of student behaviour in open and distance education in computers using Bayesian networks." Computers \& Education 43 (4):345-359.

Zhang, Peng, Olivier Deschenes, Kyle Meng, and Junjie Zhang. 2017. Temperature effects on productivity and factor reallocation: Evidence from a half million chinese manufacturing plants. IZA Institute of Labor Economics. 
Table 1

Descriptors of samples

\begin{tabular}{cccc}
\hline & Australia & China & All \\
\hline Sample size & 94 & 64 & 305 \\
Mean age & 24.11 & 24.42 & 25.31 \\
$\%$ male & $(\mathrm{SD}=7.807)$ & $(\mathrm{SD}=3.648)$ & $(\mathrm{SD}=6.36)$ \\
& $47.9 \%$ & $34.4 \%$ & $46.9 \%$ \\
\hline Pursuing diploma & $3(3.2 \%)$ & $6(9.4 \%)$ & $11(3.6 \%)$ \\
Pursuing bachelors & $54(57.4 \%)$ & $11(17.2 \%)$ & $90(29.4 \%)$ \\
Pursuing masters/ PhD & $25(26.5 \%)$ & $47(73.4 \%)$ & $188(61.6 \%)$ \\
\hline Working casually/ part-time & $64(68.1 \%)$ & $42(65.6 \%)$ & $171(56.0 \%)$ \\
Working in professional & & & \\
discipline & $25(26.6 \%)$ & $14(21.9 \%)$ & $107(35.1 \%)$ \\
Not employed & $5(5.3 \%)$ & $8(12.5 \%)$ & $24(7.9 \%)$ \\
\hline
\end{tabular}

Table 2

Cronbach's Alpha for survey questions

\begin{tabular}{lllll}
\hline & Australia & China & All & \# of items \\
\hline Self-efficacy & .707 & .785 & .720 & 8 \\
Attitude & .882 & .833 & .803 & 16 \\
Behaviour & .688 & .578 & .673 & 11 \\
\hline
\end{tabular}


Table 3

t-test statistics and independent sample test statistics of environmentally friendly behaviour and attitude variables: Australia/China

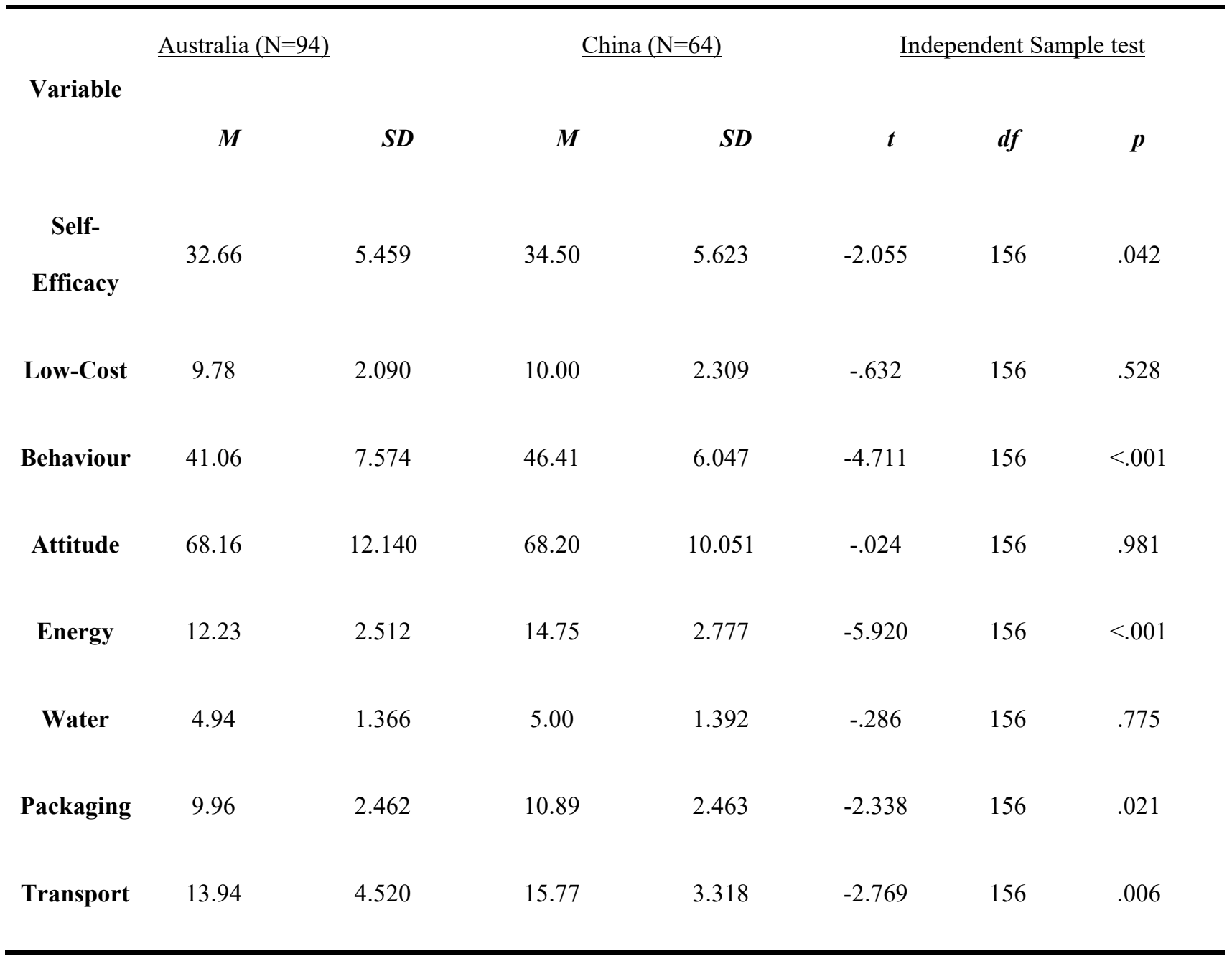


Table 4

Pearson Correlations between self-efficacy and other variables.

\begin{tabular}{|c|c|c|c|c|c|c|c|c|c|}
\hline \multirow[t]{2}{*}{ Scale } & \multicolumn{3}{|c|}{ All } & \multicolumn{3}{|c|}{$\underline{\text { Australia }}$} & \multicolumn{3}{|c|}{ China } \\
\hline & $\mathrm{r}$ & $\mathrm{P}$ & $\mathrm{N}$ & $\mathrm{r}$ & $\mathrm{P}$ & $\mathrm{N}$ & $\mathrm{r}$ & $\mathrm{P}$ & $\mathrm{N}$ \\
\hline Attitude & .840 & $<.001$ & 305 & .886 & $<.001$ & 94 & .930 & $<.001$ & 64 \\
\hline Low-Cost & .364 & $<.001$ & 305 & .346 & .001 & 94 & .348 & .005 & 64 \\
\hline Behaviour & .458 & $<.001$ & 305 & .577 & $<.001$ & 94 & .547 & $<.001$ & 64 \\
\hline Energy & .349 & $<.001$ & 305 & .342 & .001 & 94 & .341 & .006 & 64 \\
\hline Water & .259 & $<.001$ & 305 & .218 & .035 & 94 & .353 & .004 & 64 \\
\hline Packaging & .403 & $<.001$ & 305 & .523 & $<.001$ & 94 & .360 & .003 & 64 \\
\hline Transport & .260 & $<.001$ & 305 & .426 & $<.001$ & 94 & .295 & .018 & 64 \\
\hline
\end{tabular}


Table 5

Pearson Correlations between attitude and other variables.

\begin{tabular}{|c|c|c|c|c|c|c|c|c|c|}
\hline \multirow[t]{2}{*}{ Scale } & \multicolumn{3}{|c|}{$\underline{\text { All }}$} & \multicolumn{3}{|c|}{$\underline{\text { Australia }}$} & \multicolumn{3}{|c|}{$\underline{\text { China }}$} \\
\hline & $\mathrm{r}$ & $\mathrm{P}$ & $\mathrm{N}$ & $\mathrm{r}$ & $\mathrm{P}$ & $\mathrm{N}$ & $r$ & $\mathrm{P}$ & $\mathrm{N}$ \\
\hline Self-efficacy & .840 & $<.001$ & 305 & .886 & $<.001$ & 94 & .930 & $<.001$ & 64 \\
\hline Low-Cost & .387 & $<.001$ & 305 & .427 & .001 & 94 & .411 & .005 & 64 \\
\hline Behaviour & .448 & $<.001$ & 305 & .615 & $<.001$ & 94 & .523 & $<.001$ & 64 \\
\hline Energy & .344 & $<.001$ & 305 & .385 & .001 & 94 & .351 & .004 & 64 \\
\hline Water & .259 & $<.001$ & 305 & .279 & .007 & 94 & .410 & .001 & 64 \\
\hline Packaging & .381 & $<.001$ & 305 & .546 & $<.001$ & 94 & .287 & .022 & 64 \\
\hline Transport & .258 & $<.001$ & 305 & .435 & $<.001$ & 94 & .275 & .028 & 64 \\
\hline
\end{tabular}


Figure 1 - Naïve BN structure

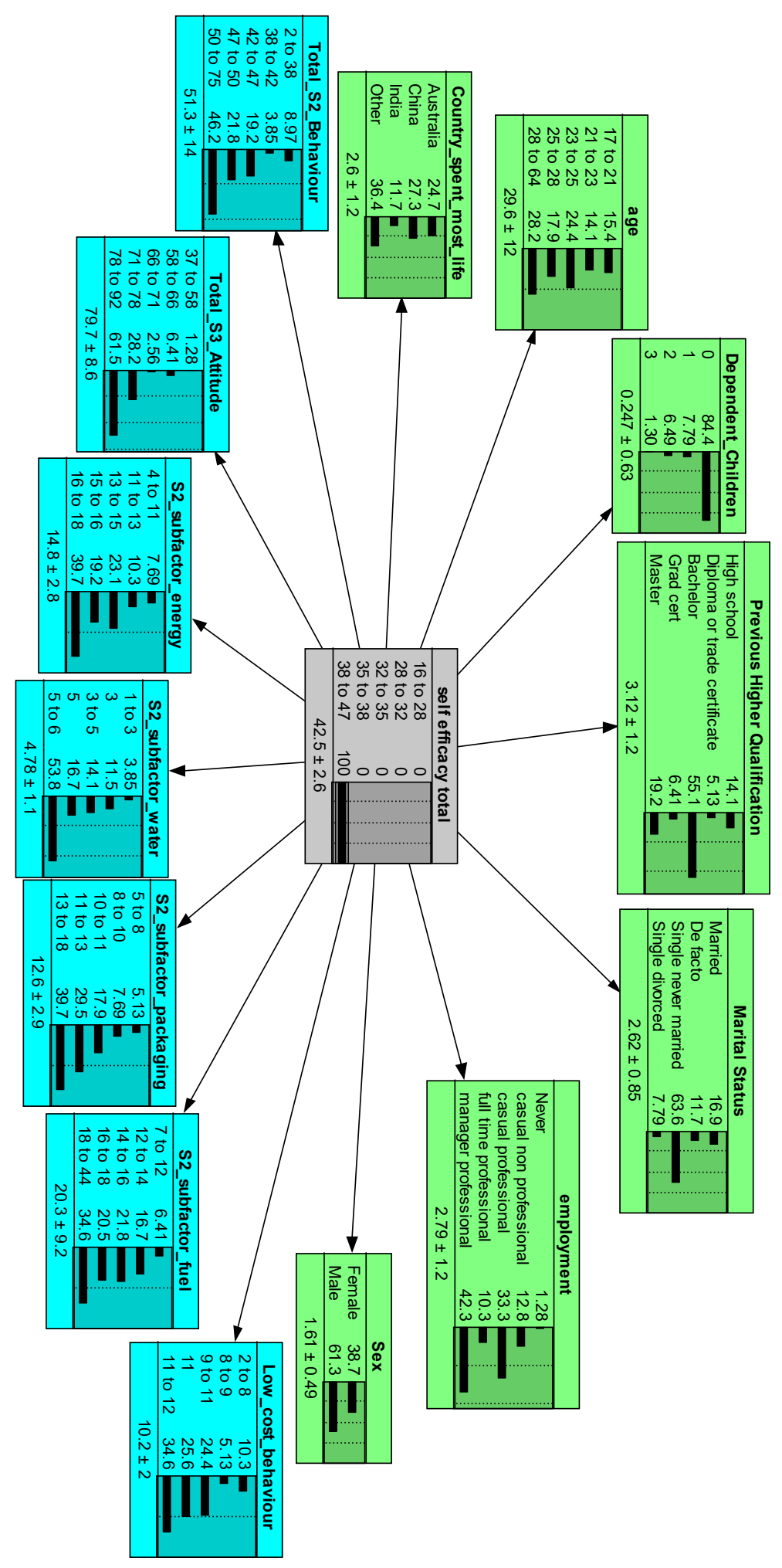


Figure 2 - Self Organising map for BN key parameters
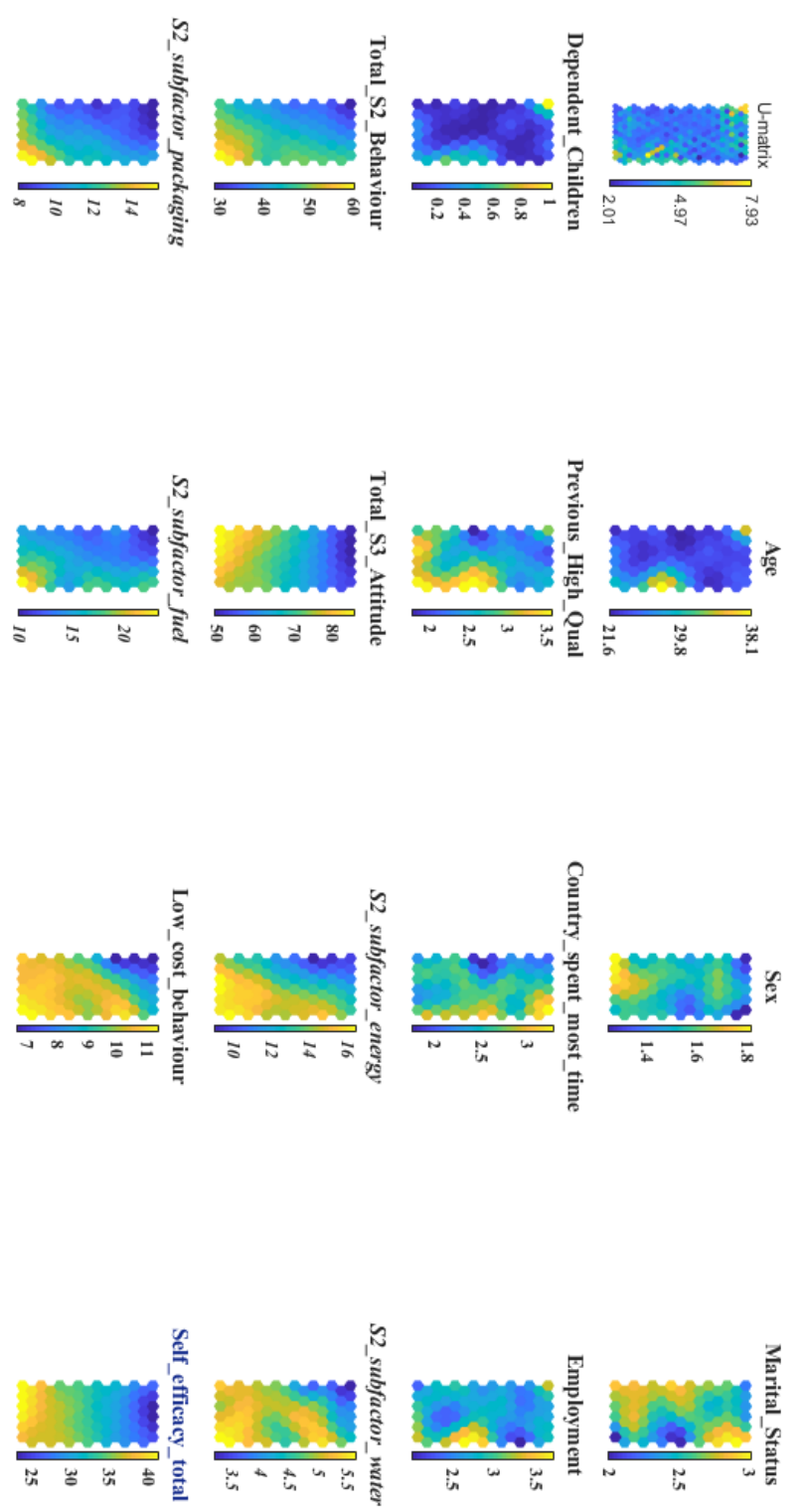
Figure 3 - Relationships between self-efficacy score and probability of certain features; direct relationships

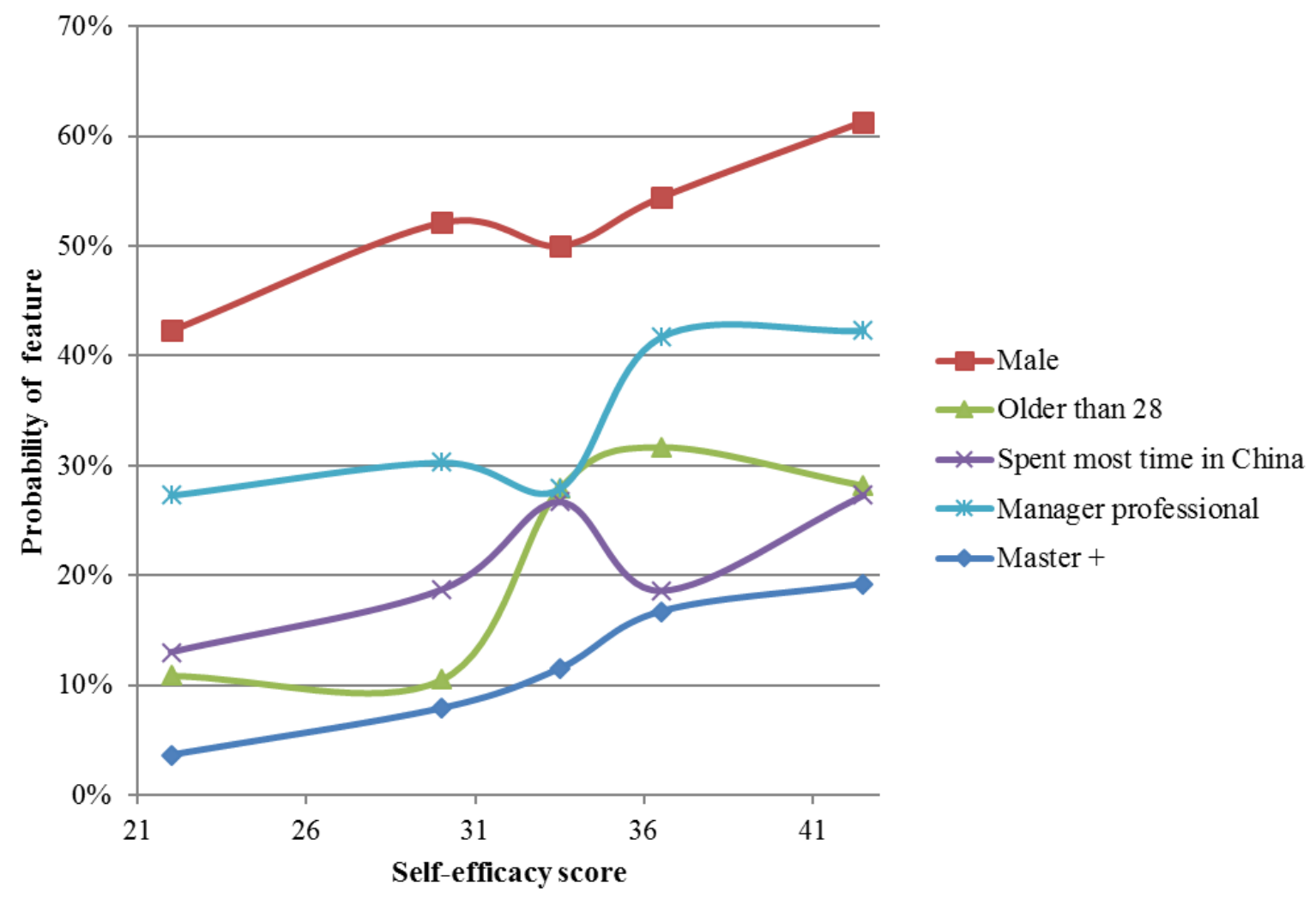


Figure 4 - Relationships between self-efficacy score and probability of certain features; inverse relationships

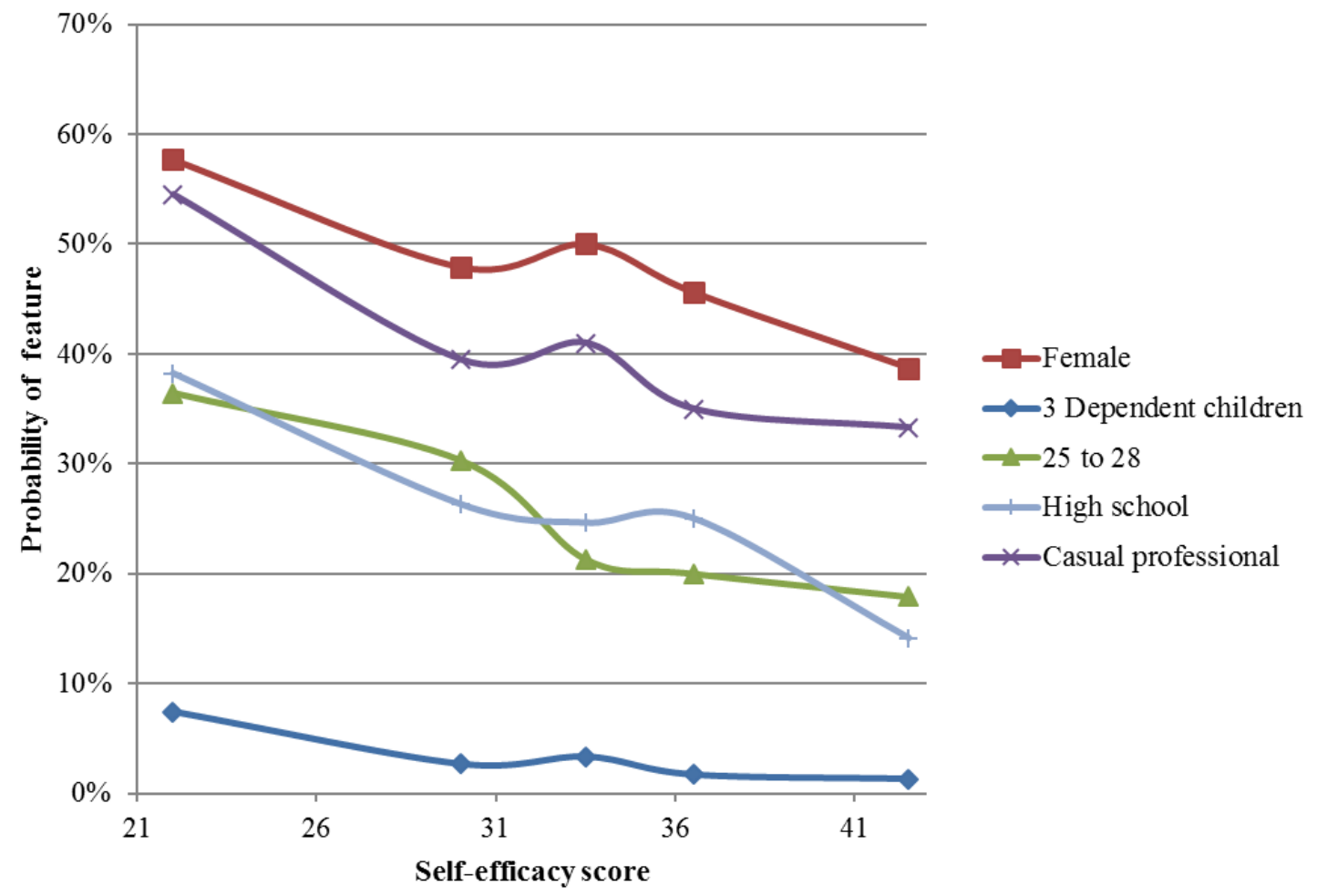




\section{Appendix - Survey}

The following questions ask about you and your beliefs about the environment. Please follow the instructions and complete the questions by choosing (circle) a response to each question from those provided.

Section 1. Demographic Questions

\begin{tabular}{|c|c|c|c|c|c|c|c|}
\hline \multicolumn{4}{|c|}{ Question } & \multicolumn{4}{|c|}{ Response } \\
\hline 1. & Age & & & & & & \\
\hline 2. & Sex & Female & Male & & & & \\
\hline 3. & Marital status & Married & $\begin{array}{l}\text { In a marriage- } \\
\text { like } \\
\text { relationship } \\
\text { (eg: living } \\
\text { together/ } \\
\text { defacto/long- } \\
\text { term) } \\
\end{array}$ & $\begin{array}{l}\text { Single, never } \\
\text { married }\end{array}$ & $\begin{array}{l}\text { Single, } \\
\text { widowed/ } \\
\text { divorced }\end{array}$ & & \\
\hline 4. & Dependent Children & 0 & 1 & 2 & 3 & 4 or more & \\
\hline 5. & $\begin{array}{lr}\text { Previous } & \text { highest } \\
\text { qualification: } & \text { Highest } \\
\text { qualification } & \text { obtained } \\
\text { prior to commencing your } & \\
\text { current } & \text { studies } \\
\text { (completed) } & \\
\end{array}$ & High School & $\begin{array}{l}\text { Sub-Bachelor's } \\
\text { Degree } \\
\text { (Diploma, } \\
\text { Trade } \\
\text { Certificate, } \\
\text { etc.) } \\
\end{array}$ & $\begin{array}{l}\text { Bachelor (inc. } \\
\text { with Hons.) }\end{array}$ & $\begin{array}{l}\text { Graduate } \\
\text { Cert/Dip }\end{array}$ & $\begin{array}{l}\text { Master's or } \\
\text { Professional } \\
\text { Doctorate }\end{array}$ & $\mathrm{PhD}$ \\
\hline 6. & $\begin{array}{l}\text { Discipline in which you } \\
\text { obtained your previous } \\
\text { highest qualification }\end{array}$ & & & & & & \\
\hline 7. & $\begin{array}{l}\text { Country in which you } \\
\text { obtained your previous } \\
\text { highest qualification }\end{array}$ & & & & & & \\
\hline 8. & Current studies & & & $\begin{array}{l}\text { Bachelor (inc. } \\
\text { with Hons.) }\end{array}$ & $\begin{array}{l}\text { Graduate } \\
\text { Cert/ Dip }\end{array}$ & $\begin{array}{c}\text { Master's or } \\
\text { Professional } \\
\text { Doctorate }\end{array}$ & $\mathrm{PhD}$ \\
\hline 9. & Country of Birth & & & & & & \\
\hline 10. & $\begin{array}{l}\text { Country in which you } \\
\text { spent most of your life }\end{array}$ & & & & & & \\
\hline 11. & First language & & & & & & \\
\hline 12. & Employment history & $\begin{array}{c}\text { Never } \\
\text { Employed }\end{array}$ & $\begin{array}{l}\text { Casual or non- } \\
\text { professional } \\
\text { work only }\end{array}$ & $\begin{array}{l}\text { Casual or } \\
\text { sporadic work } \\
\text { in my } \\
\text { professional } \\
\text { discipline }\end{array}$ & $\begin{array}{l}\text { Worked in my } \\
\text { professional } \\
\text { discipline }\end{array}$ & $\begin{array}{l}\text { Manager in } \\
\text { my } \\
\text { professional } \\
\text { discipline }\end{array}$ & \\
\hline
\end{tabular}

Section 2. Behavioural questions related to carbon dioxide emissions

Please answer the following questions using the response options provided (circle the response that best describes you).

\begin{tabular}{|c|c|c|c|c|c|c|c|}
\hline Que & tion & $\begin{array}{l}\text { N/a or } \\
\text { cannot }\end{array}$ & Never & $\begin{array}{l}\text { Not } \\
\text { very }\end{array}$ & $\begin{array}{l}\text { Quite } \\
\text { often }\end{array}$ & $\begin{array}{l}\text { Very } \\
\text { often }\end{array}$ & Always \\
\hline 13. & Turn your TV off at the wall each night & 1 & 2 & 3 & 4 & 5 & 6 \\
\hline 14. & $\begin{array}{l}\text { Switch off lights in rooms that aren't } \\
\text { being used }\end{array}$ & 1 & 2 & 3 & 4 & 5 & 6 \\
\hline 15. & $\begin{array}{l}\text { Turn off the tap while you brush your } \\
\text { teeth }\end{array}$ & 1 & 2 & 3 & 4 & 5 & 6 \\
\hline 16. & $\begin{array}{l}\text { Put more clothes on when you feel } \\
\text { cold rather than putting the heating } \\
\text { on or turning it up }\end{array}$ & 1 & 2 & 3 & 4 & 5 & 6 \\
\hline 17. & $\begin{array}{l}\text { Decide not to buy something because } \\
\text { you feel it has too much packaging }\end{array}$ & 1 & 2 & 3 & 4 & 5 & 6 \\
\hline 18. & $\begin{array}{l}\text { Buy recycled paper products such as } \\
\text { toilet paper or tissues }\end{array}$ & 1 & 2 & 3 & 4 & 5 & 6 \\
\hline 19. & $\begin{array}{l}\text { Take your own shopping bag when } \\
\text { shopping }\end{array}$ & 1 & 2 & 3 & 4 & 5 & 6 \\
\hline 20. & $\begin{array}{l}\text { Use public transport (e.g. bus, train) } \\
\text { rather than travel by car }\end{array}$ & 1 & 2 & 3 & 4 & 5 & 6 \\
\hline 21. & Walk or cycle for short journeys less & 1 & 2 & 3 & 4 & 5 & 6 \\
\hline
\end{tabular}


22. Car share with others who need to

2

3

4

5

6

make a similar journey

23. Take fewer flights when possible

1

2

3

45

6

Section 3. Questions on attitudes and beliefs regarding climate change

Please answer the following questions using the response options provided (circle the response that best describes you). Question

\begin{tabular}{|c|c|c|c|c|c|c|c|}
\hline \multicolumn{2}{|c|}{ Question } & \multirow{2}{*}{$\begin{array}{l}\text { Strongly } \\
\text { Disagree } \\
1\end{array}$} & \multirow{2}{*}{ Disagree } & \multirow{2}{*}{$\begin{array}{c}\text { Somewhat } \\
\text { Disagree }\end{array}$} & \multirow{2}{*}{$\begin{array}{c}\text { Somewhat } \\
\text { Agree }\end{array}$} & \multirow{2}{*}{ Agree } & \multirow{2}{*}{$\begin{array}{c}\text { Agree } \\
6\end{array}$} \\
\hline 24. & $\begin{array}{l}\text { I am happy with what I do in relation to my } \\
\text { current lifestyle to help the environment }\end{array}$ & & & & & & \\
\hline 25. & $\begin{array}{l}\text { When I think of my current lifestyle, I don't } \\
\text { really do anything that is environmentally- } \\
\text { friendly }\end{array}$ & 6 & 5 & 4 & 3 & 2 & 1 \\
\hline 26. & $\begin{array}{l}\text { When I think of my current lifestyle, I'm } \\
\text { environmentally-friendly in most things I do }\end{array}$ & 1 & 2 & 3 & 4 & 5 & 6 \\
\hline 27. & $\begin{array}{l}\text { To what extent do you agree that being } \\
\text { "green" is an alternative lifestyle, it's not for } \\
\text { the majority }\end{array}$ & 6 & 5 & 4 & 3 & 2 & 1 \\
\hline 28. & $\begin{array}{l}\text { I don't believe my behaviour and everyday } \\
\text { lifestyle contribute to climate change }\end{array}$ & 6 & 5 & 4 & 3 & 2 & 1 \\
\hline 29. & $\begin{array}{l}\text { I would be prepared to pay more for } \\
\text { environmentally-friendly products }\end{array}$ & 1 & 2 & 3 & 4 & 5 & 6 \\
\hline 30. & $\begin{array}{l}\text { If things continue on their current course, we } \\
\text { will soon experience a major environmental } \\
\text { disaster }\end{array}$ & 1 & 2 & 3 & 4 & 5 & 6 \\
\hline 31. & $\begin{array}{l}\text { The so-called 'environmental crisis' facing } \\
\text { humanity has been greatly exaggerated }\end{array}$ & 6 & 5 & 4 & 3 & 2 & 1 \\
\hline 32. & $\begin{array}{l}\text { Climate change is beyond control-it's too late } \\
\text { to do anything about it }\end{array}$ & 6 & 5 & 4 & 3 & 2 & 1 \\
\hline 33. & $\begin{array}{l}\text { The effects of climate change are too far in the } \\
\text { future to really worry me }\end{array}$ & 6 & 5 & 4 & 3 & 2 & 1 \\
\hline 34. & $\begin{array}{l}\text { Any changes I make to help the environment } \\
\text { need to fit in with my lifestyle }\end{array}$ & 6 & 5 & 4 & 3 & 2 & 1 \\
\hline 35. & $\begin{array}{l}\text { It's not worth me doing things to help the } \\
\text { environment if others don't do the same }\end{array}$ & 6 & 5 & 4 & 3 & 2 & 1 \\
\hline 36. & $\begin{array}{l}\text { It's not worth my country trying to combat } \\
\text { climate change, because other countries will } \\
\text { just cancel out what we do. }\end{array}$ & 6 & 5 & 4 & 3 & 2 & 1 \\
\hline 37. & $\begin{array}{l}\text { It's not worth me trying to combat climate } \\
\text { change through my individual behaviours, } \\
\text { because other people's actions will just cancel } \\
\text { out what I do }\end{array}$ & 6 & 5 & 4 & 3 & 2 & 1 \\
\hline 38. & $\begin{array}{l}\text { People around the world will be directly } \\
\text { affected by climate change within the next } 30 \\
\text { years }\end{array}$ & 1 & 2 & 3 & 4 & 5 & 6 \\
\hline 39. & $\begin{array}{l}\text { If we continue as we are people around the } \\
\text { world will be catastrophically affected by }\end{array}$ & 1 & 2 & 3 & 4 & 5 & 6 \\
\hline
\end{tabular}

